\title{
Research on Spatial Arrangement of Metro Station Floor Facilities Based on Pathfinder
}

\author{
Shouguo Yang*, Jia Jin, Xuefu Lu \\ College of Safety Science \& Engineering, Xi'an University of Science and Technology, Xi'an, China \\ Email address: \\ Yangsg@xust.edu.cn (Shouguo Yang),461696959@qq.com (Jia Jin),260639948@qq.com (Xuefu Lu) \\ ${ }^{*}$ Corresponding author
}

To cite this article:

Shouguo Yang, Jia Jin, Xuefu Lu. Research on Spatial Arrangement of Metro Station Floor Facilities Based on Pathfinder. American Journal of Civil Engineering. Vol. 7, No. 6, 2019, pp. 147-151. doi: 10.11648/j.ajce.20190706.11

Received: November 15, 2019; Accepted: December 3, 2019; Published: December 9, 2019

\begin{abstract}
The process of China's large-scale urbanization is constantly advancing, and public transportation problems are increasingly prominent. In recent years, major cities have been building subways. The advantages of the subway, such as fast and low carbon, have become an important means for large cities to solve urban public transportation. With the development of urban subway construction technology and operation scale and the continuous improvement of people's safety concept, the problem of evacuation of people in emergencies such as fires has increasingly aroused people's understanding. In order to explore the influence of the location of the facility space on the station floor to the evacuation of people in the event of an emergency, this paper optimizes the analysis of the traffic facilities such as the automatic ticket gate and the guide railing in the public area of the subway based on the pathfinder evacuation software. The location of the facility space at the station floor of the subsequent construction has been actively assisted. The simulation results show that the opening of the guide rail at the gate and the entrance and exit of the security inspection has a restraining effect on the evacuation of personnel; the spatial arrangement of the subway gate has a significant impact on the evacuation of personnel, and the layout of the distributed gates is not correct. The personnel at the exit of the escalator caused blockages, which was better than the centralized arrangement.
\end{abstract}

Keywords: Evacuation, Metro, Pathfinder, Spatial Layout

\section{Introduction}

With the development of China's economy and the increasingly serious problems of ground public transportation, the advantages of the rapid and low-carbon of metro have become an important vehicles for some cities to solve urban public transportation. However, the subway space is small and crowded. In the case of an emergency, it is easy to cause group death. How to improve the rapid evacuation of personnel under sudden conditions such as subway fires or terrorist attacks is an urgent problem to be solved. The subway fire is compared with the fire of the ground building, and its uniqueness is mainly manifested in: (1) Space. The subway is generally underground, the space is relatively closed, and it is continuous. (2) Limited entrances and exits. The number of subway entrances and exits is limited. Once the fire occurs, the entrance and exit not only have the function of ventilation and smoke exhaustion, but also the only way for firefighters to carry out fire rescue. (3) Lighting. Because the subway system uses artificial lighting because it is buried deep underground, once the power outage lighting will be greatly affected.

Domestic and foreign scholars have studied the factors affecting the evacuation of people in emergencies. For example, Lijuan $\mathrm{Hu}$ and other scholars have studied the number of station staff [1-6], export conditions and psychological behaviors for emergency evacuation in the subway emergency. Influence: Some scholars have studied the factors such as subway building structure and facility layout. For example, Changkun Chen [7] and Shuangqing Liu used numerical simulation methods to study the influence of the inner and outer guide rails on the evacuation efficiency of subway stations [8-9]. At home and abroad, research on personnel psychology, smoke spread and building structure is carried out. The layout of subway station and hall facilities focuses on the study of single facilities, but the public areas of the station hall include diversion railings and gates [10-13]. Based on the Pathfinder, this paper analyse the impact of 
facility layout on the evacuation of public areas in the subway station hall and provide a reasonable facility layout plan to subway design.

\section{Evacuation Models and Results}

\subsection{Evacuation Software Introduction}

Pathfinder software is an emergency evacuation simulation engineering software developed by Thunderhead Engineering of the United States. It provides users with a graphical user interface for simulation design and operation, as well as $2 \mathrm{D}$ and $3 \mathrm{D}$ visualization tools for analyzing results. The software consists of a graphical user interface module, a simulation calculation module, and a three-dimensional result display module. The human motion mode in Pathfinder includes SFPE and Steering. The SFPE model uses the SFPE concept in the Fire Protection Design Manual, in which population density affects the rate of movement of people, and the width of the exit determines the flow of people, and people can overlap in space while exercising. The Steering model combines path planning, guidance mechanisms, and collision handling to control personnel movement. This model can more realistically reflect the behavior of people during emergency evacuation [14-15]. This paper adopts the Steering model and uses Pathfinder to establish the platform and station floor model of the No. 4 subway line in Xi'an, China.

\subsection{Metro Building Structure Parameters}

According to the building structure parameters of the station platform and the station hall of Xi'an Metro Line 4 (He ping men Station and University of Architecture and Technology), an evacuation model for emergencies is established. There are three passages from the platform to the station hall of He ping men Station, two escalators are arranged on both sides, stairs and barrier-free elevators are arranged in the middle, as shown in Figure 1; and two escalators are arranged on both sides of the University of Construction and Technology, and the middle of the escalator is $2 \mathrm{~m}$ wide. The stairs are in the middle of the elevator, as shown in Figure 2.

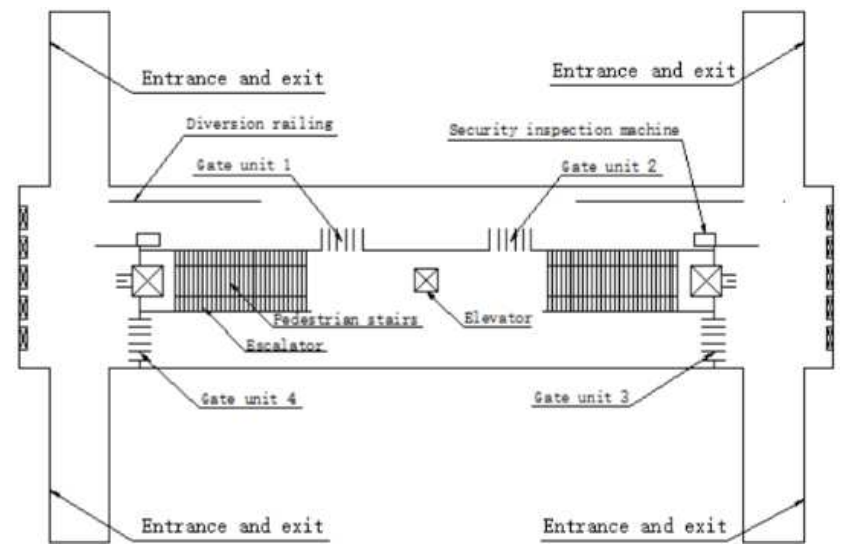

Figure 1. Arrangement of stairs in the middle (central arrangement of gates).

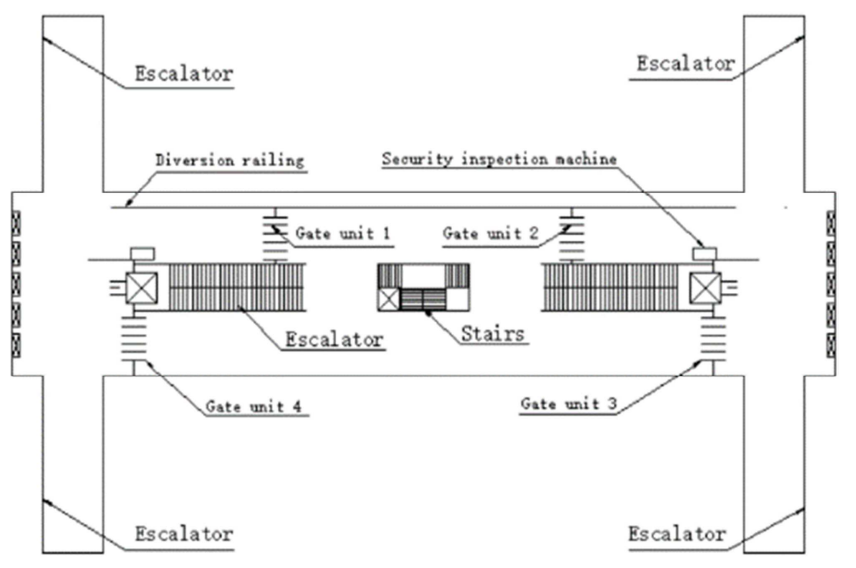

Figure 2. Stairs are not arranged in the middle (distribution of gates).

\subsection{Gate Parameter Setting}

The automatic ticket gate is one of the important facilities of the subway facility system. In the case of fire, the location, quantity and type of the gate space play an important role in the evacuation efficiency of personnel. The subway gate is the key to passengers entering and leaving the subway station hall, and it is also the focus of this paper. The parameters of the automatic ticket gates used in Xi'an Metro are shown in Table 1.

Table 1. Metro gate parameters.

\begin{tabular}{llllll}
\hline Facility & Type & Direction & $\begin{array}{l}\text { Gate } \\
\text { width/m }\end{array}$ & $\begin{array}{l}\text { Gate } \\
\text { length/m }\end{array}$ & Layout \\
\hline Gate & $\begin{array}{l}\text { Threshold } \\
\text { gate }\end{array}$ & one-way & 0.55 & 1.50 & $\begin{array}{l}\text { centralized } \\
\text { / istributed }\end{array}$ \\
\hline
\end{tabular}

\subsection{Evacuation Personnel Parameters}

According to Xi'an subway passenger flow statistics, the average daily passenger flow of Xi'an Metro Line 4 can reach 404,300 , of which 476,800 passengers can be reached during major festivals or major gatherings. This paper mainly analyzes the passengers passing through the gates in the event of a fire in the evening peak hours, of which 500 people and 200 people are on the platform and station floor of the subway. The speed of evacuation of personnel is affected by many factors including age, shoulder width, path selection, exit selection, and walking speed. The parameters such as the highest walking speed, up and down stairs speed, shoulder width, back thickness and height of various personnel in the subway station are based on China's human body measurement standards, the US NFPA 130 specification and related literature, and the speed of various personnel in the subway station is comprehensively obtained. And shape, as shown in Table 2.

Table 2. Evacuation personnel attributes.

\begin{tabular}{lllll}
\hline Type & Child & Adolescent & Middle-aged & Senior \\
\hline $\begin{array}{l}\text { Body size } / \mathrm{m} \\
\text { Movement }\end{array}$ & 0.3 & 0.4558 & 0.4558 & 0.4558 \\
$\begin{array}{l}\text { speed } /(\mathrm{m} / \mathrm{s}) \\
\text { proportion } / \%\end{array}$ & 0.8 & 1.51 & 1.39 & 1.00 \\
\hline
\end{tabular}




\subsection{Working Conditions Setting}

According to the stairs setting of the subway station, the space location of the gate, the guide railing and other factors, the evacuation model is set up. The working conditions are shown in Table 3.

Table 3. Parameter settings of each working condition.

\begin{tabular}{|c|c|c|c|c|c|c|c|}
\hline Working condition & 1 & 2 & 3 & 4 & 5 & 6 & 7 \\
\hline Gate arrangement & Centralized & distributed & Centralized & distributed & distributed & distributed & Centralized \\
\hline Middle staircase & No & Yes & Yes & Yes & Yes & No & Yes \\
\hline Diversion railing & $\begin{array}{l}\text { Crossing } \\
\text { street }\end{array}$ & $\begin{array}{l}\text { Crossing } \\
\text { street }\end{array}$ & $\begin{array}{l}\text { Crossing } \\
\text { street }\end{array}$ & Crossing street & Crossing street & No & Exemption channel \\
\hline Gate and stairs distance $/ \mathrm{m}$ & - & 1 & - & 2 & 3 & 3 & - \\
\hline
\end{tabular}

\section{Results Analysis and Discussion}

\subsection{Analysis of the Spatial Position of Subway Gates}

In the case of fire, the disaster-stricken personnel inside the subway escaped from the incident site through stairs, escalators and other facilities, and bottlenecks appeared at the stairway. When the fire occurs, the descending escalator automatically stops running and can be used as a staircase.
Through the pathfinder personnel evacuation software simulation subway station platform space with the central staircase working conditions 2, 4, 5 and working condition 6 model, found that the evacuated people from the platform level evacuation time is $54.0 \mathrm{~S} \sim 73.0 \mathrm{~S}$; and there is no layout of the central stairs 1 and working conditions 3 evacuated people were $89.0 \mathrm{~S}$ and $87.0 \mathrm{~S}$. The evacuation time of the platform at each working condition is shown in Table 4.

Table 4. Evacuation time of each working condition.

\begin{tabular}{lllllll}
\hline Working condition & $\mathbf{1}$ & $\mathbf{2}$ & $\mathbf{3}$ & $\mathbf{4}$ & $\mathbf{5}$ & $\mathbf{6}$ \\
\hline Platform evacuation time/s & 89.0 & 56.0 & 87.0 & 54.0 & 56.0 & 73.0 \\
Total evacuation time/s & 144.8 & 134.8 & 159.0 & 136.0 & 93.0 & 127.8 \\
\hline
\end{tabular}

Through the analysis of working conditions 1 to 6 , the evacuation efficiency of the affected people on the platform is related to the space setting position of the brake unit. The centralized arrangement of the gates makes it easy for people who choose to evacuate from the brake units 1 and 2 . The outlet is blocked, which inhibits the evacuation efficiency of the disaster victims on the platform. The inhibition rate is $16 \%$ to $39.3 \%$. Through simulations, it is found that the affected people formed crowding at the entrance and exit of the subway gates, reducing the evacuation efficiency of personnel. As shown in Figure 3 and Figure 4, the working condition 3 and the working condition 5 evacuate the dynamic map and the position where the blockage occurs.

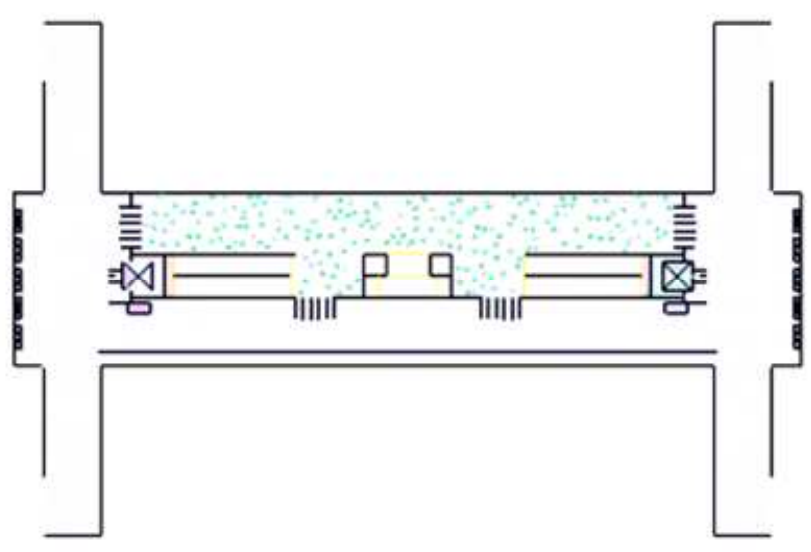

Working condition 3,0s evacuation map

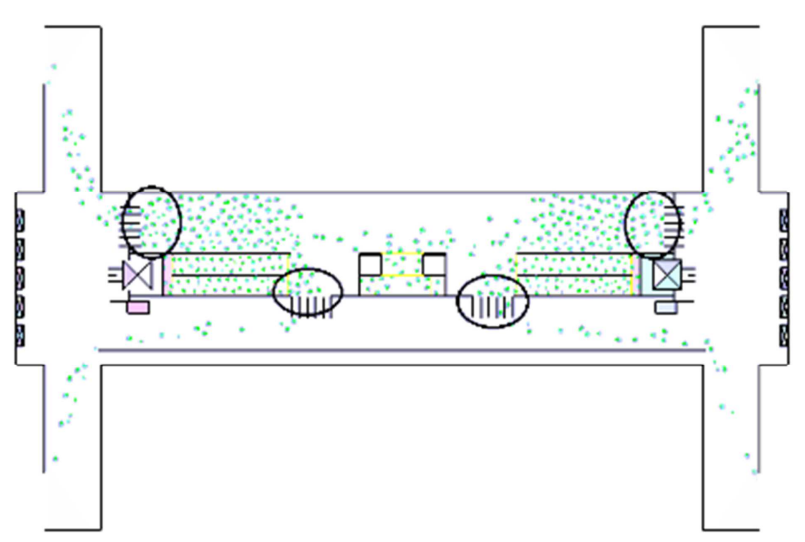

Working condition $3,45.4$ s evacuation map

Figure 3. Dynamic situation of evacuation time of working condition 3.

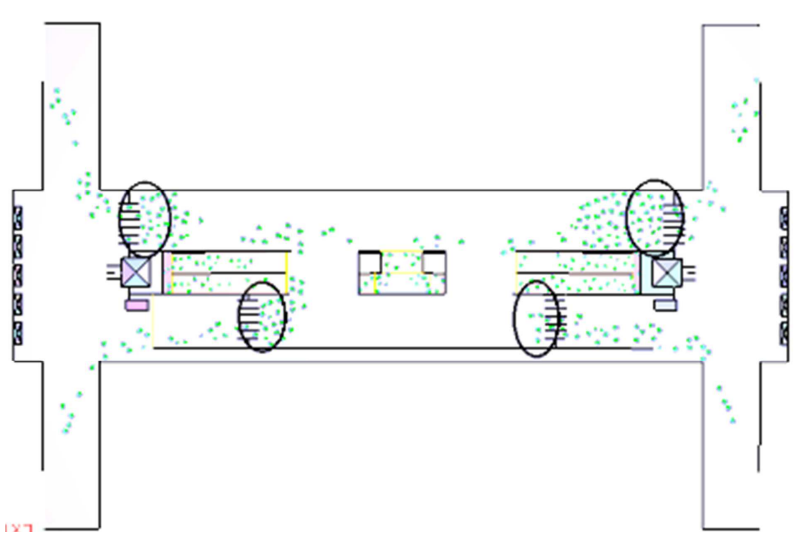

Working condition $5,13.5 \mathrm{~s}$ evacuation map 


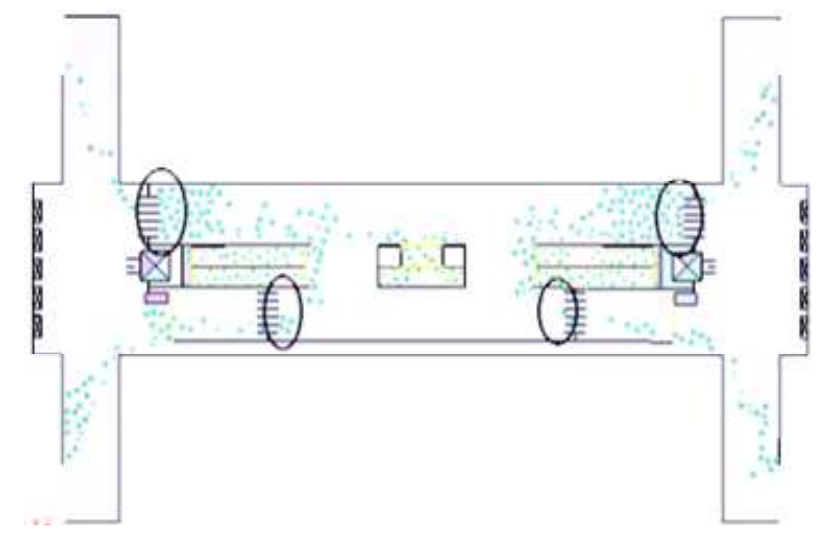

Working condition 5, 29.0s evacuation map

Figure 4. Dynamic situation of evacuation time of working condition 5.

\subsection{Influence of Pedestrian Crossings and Inspection-free Passages on Evacuation of Personnel}

According to the requirements of urban road planning, combined with road planning, station location and ease of ground transportation, underground crossings are arranged at the subway station floor to facilitate public travel. The underground crossing channel is divided into a station crossing passage and a station crossing passage at the general crossing or at the intersection side. The main research in this paper is that there is a crossing passage in the station. Railings are added to the passenger passages on the station floor level, so that the functional division is clear and the impact of cross-street passenger flow on operations is reduced, but the width of the passenger passage is reduced.

Through the simulation comparison of the working condition 2 and the working condition 4 evacuation, it can be found that the setting of the crossing channel has no significant effect on the evacuation of the disaster victims in the subway station; the working condition 2 and the working condition 4 are different by $1.2 \mathrm{~S}$. The working condition 3 and the working condition 7 are different by $4.5 \mathrm{~S}$. The difference in evacuation time between working condition 3 and working condition 5 is still mainly due to the spatial position setting of the gate. The setting of the crossing channel in the subway station should be considered in combination with the facilities such as the space arrangement of the gate. The research proposed in this paper suggests a distributed arrangement. The simulation found that in the case of fire, the evacuation of the guide rail at the entrance of the subway security check has a rectifying effect but also has a restraining effect, which slows down the evacuation speed of the personnel. Therefore, due to the convenience of management and charging during the daily operation of the subway station, a barrier will be installed in the subway station hall. However, in the event of an emergency requiring emergency evacuation, the barrier needs to be removed in time to enable the passengers to evacuate quickly and reduce the detention time to achieve the goal of reducing casualties.

In summary, under daily operation, the security inspection entrance and exit of the subway and the diversion railing at the inspection-free passage are beneficial to improve the efficiency of passengers entering the station; however, in the case of fire, the unreasonable diversion railing at the exit affects the evacuation efficiency. In the literature [16], it has also been found that reasonable railing arrangement is conducive to evacuation of personnel.

\section{Conclusion}

Based on the Pathfinder software, the evacuation simulation of the impact of the space layout of the subway station hall on the evacuation of the subway is carried out. It is found that the spatial arrangement of the distributed gates is better than the centralized arrangement. The inhibition rate of the centralized distribution is $16 \% \sim 39.3 \%$. The reason why the distributed arrangement of the gates does not cause blockages to the personnel at the exit of the escalator, and the moving speed of the affected personnel is suppressed. Through the simulation of the channel space layout of different types of stations, the subway gates should adopt a distributed arrangement in the case of setting up the crossing passages, and the crowding phenomenon of the disaster-stricken personnel in the evacuation process mainly occurs at the entrance and exit of the stairs and gates and the corners. Waiting for the location. In the event of an emergency requiring emergency evacuation, the diversion railing at the entrance and exit of the subway security check will have a negative effect on evacuation of personnel. In order to ensure the smooth passage of personnel, the evacuation speed of personnel, the guide rails of the subway security checkpoint, and the subway gates and other facilities are provided. It should be opened in time. In the event of an emergency requiring emergency evacuation, the diversion rail.

\section{References}

[1] Hu Lijuan, Yao Jialin, Zheng Liang. Study on Emergency Evacuation Simulation of Subway Station Personnel Based on NetLogo [J]. Journal of Railway Science and Engineering, 2017, 14 (12): 2730-2737.

[2] Zu Mingmin, Cai Zhiyong, Yue Shidong. Research on Emergency Evacuation of a Subway Station Based on Numerical Simulation [J]. Safety Science, 2019, 40 (04): 16-19.

[3] Yang Hui, Dong Bingyan, Zhang Sijian. Study on Fire Safety Evacuation Simulation of a Subway Station [J]. Fire Science and Technology, 2019, 38 (03): 368-371.

[4] Shi J, Wen S, Zhao X, et al. Sustainable Development of Urban Rail Transit Networks: A Vulnerability Perspective [J]. Sustainability, 2019, 11 (5).

[5] Zhang Limao, Wu Xianguo, Li Bowen, Zhai Yawei, Zhang Wei. evacuation of subway station personnel based on fire simulator and Pathfinder [J]. Science Technology and Engineering, 2018, 18 (04): 203-209.

[6] Mu Nana, Shi Congling, Xuan Xu, et al. Study on the influence of the guide railing of subway station on evacuation of personnel [J]. China Safety Production Science and Technology, 2018, 14 (12): 175-179. 
[7] Chen Zhangkun, Qin Wenlong subway station heterogeneous crowd evacuation simulation reentrant behavior analysis $[\mathrm{J}]$ China Safety Science and Technology, 2018, 14 (09): 24-30.

[8] Zhang Kecheng. Overview of Safe Evacuation of Subway Stations [J]. Shandong Industrial Technology, 2018 (02): 209.

[9] Lyu H M, Sun W J, Shen S L, et al. Flood risk assessment in metro systems of mega-cities using a GIS-based modeling approach [J]. Science of The Total Environment, 2018, 626: 1012-1025.

[10] Ying ying Xing, Jian Lu. Evaluating the effectiveness of platform screen doors for preventing metro suicides in China [J]. Journal of Affective Disorders, 2019, 253 (15): 63-68.

[11] Ronghui Tan, Qingsong He, Kehao Zhou, Peng Xie. The effect of new metro stations on local land use and housing prices: The case of Wuhan, China. [J]. Journal of Transport Geography, 2019, 79, 102488.

[12] Ling H, Jia G, Wei Z. Self-evacuation modelling and simulation of passengers in metro stations [J]. Safety Science, 2018: 127-133.

[13] Anastasios K, Despina P, Vasiliki A, et al. Evacuation Method Evaluation in Underground Metro Station [J]. International Journal of Disaster Risk Reduction, 2018, 31: 526-534.

[14] Xiao-ya Song, Yong Pan, Jun-cheng Jiang, Fan Wu, Yu-jun Ding. Numerical Investigation on the Evacuation of Passengers in Metro Train Fire [J]. Procedia Engineering, 2018, 211: 644-650.

[15] Limao Z, Mengjie L, Xianguo W, et al. Simulation-based route planning for pedestrian evacuation in metro stations: A case study [J]. Automation in Construction, 2016, 71: $430-442$.

[16] Li F, Chen S, Wang X, et al. Pedestrian Evacuation Modeling and Simulation on Metro Platforms Considering Panic Impacts [J]. Procedia - Social and Behavioral Sciences, 2014, 138: 314-322. 